\title{
$0=$ \\ Doxycycline for exacerbations of chronic obstructive pulmonary disease in outpatients: who benefits?
}

\author{
To the Editor:
}

Most patients with chronic obstructive pulmonary disease (COPD) experience exacerbations [1]. $>80 \%$ of the exacerbations are treated ambulatorily. Treatment consists of inhaled bronchodilator therapy and oral corticosteroids, whereas the contribution of antibiotics is less clear. A meta-analysis [2] recently reported less treatment failure within 4 weeks in outpatient exacerbations treated with antibiotics: $21.2 \%$ in the group treated with antibiotics versus $29.2 \%$ in the placebo group. This means that $12-13$ patients must be treated with antibiotics to prevent one treatment failure (number needed to treat: 12.5).

It remains unclear who benefits from antibiotic treatment. Restricting antibiotic treatment to those who benefit is important to prevent antibiotic overuse, the key driver of antibiotic resistance. A randomised trial by ANTHONISEN et al. [3] showed that patients with increased dyspnoea, increased sputum volume and increased sputum purulence had statistically significantly less treatment failure within 21 days when they were treated with antibiotics compared to placebo. There were no statistically significant differences in treatment failure rates in patients with only one symptom. This could not be confirmed in a more recent study [4]. Current guidelines reflect this uncertainty. The European Respiratory Society and American Thoracic Society recommend antibiotics for all ambulatory patients [5]. The Global Initiative for Chronic Obstructive Lung Disease (GOLD) recommends treating outpatients with antibiotics if they have three major symptoms (increase in dyspnoea, sputum volume and sputum purulence) or two if increased sputum purulence is one of them [1]. In contrast, the UK National Institute for Health and Care Excellence guideline advises weighing risks and benefits of antibiotics in each individual case [6].

The use of biomarkers however might be helpful: C-reactive protein-guided prescribing of antibiotics for exacerbations of COPD in primary care resulted in lower antibiotic use, with no evidence of harm [7], and in another study, primary care patients without sputum purulence, and a CRP value $<40 \mathrm{mg} \cdot \mathrm{L}^{-1}$ could be safely treated without antibiotics [4]. In addition, a procalcitonin-guided antibiotic strategy has been associated with fewer antibiotic prescriptions [8]. As these tools are not always available, additional research is needed to identify those outpatients that benefit from antibiotic therapy. The aim of the present study was to identify clinical characteristics that could guide the decision to prescribe or withheld antibiotic treatment.

For this study, we used data of all 301 patients participating in a randomised placebo-controlled trial comparing doxycycline with placebo for the treatment of COPD exacerbations in an outpatient setting [9]. Trial design, participants and procedures have been described previously [9]. In short, we recruited a cohort of patients with COPD from outpatient clinics of nine teaching hospitals and three primary care centres in the Netherlands. In cases of an exacerbation, patients were randomly assigned to receive doxycycline or a placebo. An exacerbation was defined as an event characterised by a change in patients' baseline dyspnoea, cough or sputum beyond day-to-day variability, sufficient to warrant a change in management other than optimising bronchodilator therapy [1,5]. All patients received a course of oral corticosteroids (OCS). Fever at the time of exacerbation was the most important exclusion criterion. At randomisation, clinical data including respiratory symptoms and sputum characteristics were collected.

@ERSpublications

No clinical characteristics, particularly not sputum characteristics, can guide antibiotic prescription in patients with mild to severe COPD exacerbations https://bit.ly/3e1JV8o

Cite this article as: van Velzen P, ter Riet G, Brinkman P, et al. Doxycycline for exacerbations of chronic obstructive pulmonary disease in outpatients: who benefits? ERJ Open Res 2020; 6: 000992020 [https://doi.org/10.1183/23120541.00099-2020]. 
Treatment failure was defined as the need for a new course of OCS and/or the prescription of open-label antibiotics, hospitalisation or death [10]. The presence of treatment failure was established at day 21.

We performed 33 subgroup analyses in which we compared treatment failure rates. Six were predefined in our previous publication [9]: age, sex, GOLD stage, smoking status, number of previous exacerbations in the past 3 years and treatment setting. The others were exploratory. Subgroups were based on clinical variables available at baseline or during exacerbation, including exacerbation characteristics, spirometry data, medical history, inhalation medication and health-related quality of life.

Continuous data were dichotomised; splits were based on the literature or mean/median. We repeated analyses with continuous data grouped in tertiles. For all subgroups, stratum-specific odds ratios with $95 \%$ confidence intervals and tests for interaction were calculated. For statistical analyses, we used the Mantel-Haenszel odds ratio (mhor) function from the epiDisplay package in $\mathrm{R}$ (version 3.6.1) and RStudio (version 1.2.1.335). We used a significance level of 0.05 ; therefore, given the number of comparisons, at least one interaction test is expected to be statistically significant based on chance alone [11].

301 patients were included in the trial, 150 in the doxycycline group and 151 in the placebo group. Clinical and exacerbation characteristics were generally well balanced [9].

Treatment failure rates at day 21 were 24 (16\%) out of 150 in the doxycycline group and 40 (26.5\%) out of 151 in the placebo group ( $\mathrm{p}=0.03$ ). Reasons for treatment failure were a new course of OCS in 12 patients in the doxycycline group and in seven patients in the placebo group $(p=0.28)$, open-label antibiotics in five versus 15 patients $(\mathrm{p}=0.04)$, and both OCS and open label antibiotics in seven versus 10 patients $(\mathrm{p}=0.62)$. No patients were admitted to the hospital in the doxycycline group versus eight in the placebo group ( $\mathrm{p}=0.007$ ). There were no deaths in either group.

\begin{tabular}{|c|c|c|c|c|c|}
\hline Subgroup & Doxycyline $\mathrm{n} / \mathrm{N}$ & Placebo n/N & & OR $(95 \% \mathrm{CI})$ & $\begin{array}{l}\mathrm{p} \text {-value for } \\
\text { interaction }\end{array}$ \\
\hline $\begin{array}{l}\text { Age } \\
<65 \text { years } \\
\geqslant 65 \text { years }\end{array}$ & $\begin{array}{l}11 / 74 \\
13 / 76\end{array}$ & $\begin{array}{l}15 / 66 \\
25 / 85\end{array}$ & $H_{\square-1}$ & $\begin{array}{l}1.68(0.66-4.43) \\
2.01(0.89-4.70)\end{array}$ & 0.76 \\
\hline $\begin{array}{l}\text { Sex } \\
\text { Male } \\
\text { Female }\end{array}$ & $\begin{array}{l}13 / 98 \\
11 / 52\end{array}$ & $\begin{array}{l}21 / 81 \\
19 / 70\end{array}$ & $1+\square-1$ & $\begin{array}{l}2.28(1.00-5.37) \\
1.38(0.55-3.61)\end{array}$ & 0.39 \\
\hline $\begin{array}{l}\text { GOLD stage } \\
1,2 \\
3\end{array}$ & $\begin{array}{l}16 / 102 \\
8 / 48\end{array}$ & $\begin{array}{l}28 / 103 \\
12 / 48\end{array}$ & $\sqrt{\square+}$ & $\begin{array}{l}2.00(0.96-4.28) \\
1.66(0.55-5.25)\end{array}$ & 0.76 \\
\hline $\begin{array}{l}\text { Smoking status } \\
\text { Former } \\
\text { Current }\end{array}$ & $\begin{array}{c}11 / 101 \\
13 / 49\end{array}$ & $\begin{array}{l}25 / 86 \\
15 / 65\end{array}$ & 不 & $\begin{array}{l}3.33(1.45-8.09) \\
0.83(0.32-2.16)\end{array}$ & 0.02 \\
\hline $\begin{array}{l}\text { Setting } \\
\text { GP } \\
\text { Pulmonologist }\end{array}$ & $\begin{array}{c}11 / 49 \\
13 / 101\end{array}$ & $\begin{array}{l}18 / 64 \\
22 / 87\end{array}$ & $H$ & $\begin{array}{l}1.35(0.53-3.57) \\
2.28(1.01-5.32)\end{array}$ & 0.37 \\
\hline $\begin{array}{l}\text { Frequency of exacerbations } \\
<2 \text { per year } \\
\geqslant 2 \text { per year }\end{array}$ & $\begin{array}{l}14 / 93 \\
10 / 57\end{array}$ & $\begin{array}{l}28 / 106 \\
12 / 45\end{array}$ & $\stackrel{+}{\longrightarrow \square}$ & $\begin{array}{l}2.02(0.94-4.48) \\
1.7(0.59-4.97)\end{array}$ & 0.78 \\
\hline $\begin{array}{l}\text { Exacerbation type } \\
\text { Type } 1 \\
\text { Type } 2,3\end{array}$ & $\begin{array}{l}15 / 89 \\
9 / 61\end{array}$ & $\begin{array}{l}16 / 77 \\
24 / 74\end{array}$ & H- & $\begin{array}{l}1.29(0.55-3.06) \\
2.75(1.1-7.42)\end{array}$ & 0.2 \\
\hline $\begin{array}{l}\text { Sputum purulence } \\
\text { Yes } \\
\text { No }\end{array}$ & $\begin{array}{l}7 / 55 \\
17 / 95\end{array}$ & $\begin{array}{l}19 / 64 \\
21 / 87\end{array}$ & 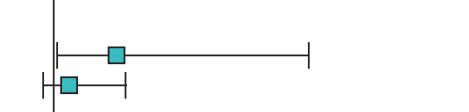 & $\begin{array}{l}2.87(1.03-8.88) \\
1.46(0.67-3.21)\end{array}$ & 0.27 \\
\hline $\begin{array}{l}\text { Increased sputum volume } \\
\text { Yes } \\
\text { No }\end{array}$ & $\begin{array}{c}5 / 35 \\
19 / 115\end{array}$ & $\begin{array}{c}12 / 34 \\
28 / 117\end{array}$ & 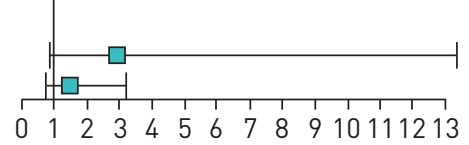 & $\begin{array}{c}2.87(0.89-13.43) \\
1.46(0.79-3.23)\end{array}$ & 0.3 \\
\hline
\end{tabular}

FIGURE 1 Subgroup analyses for patients who had treatment failure at day 21. Type 1: three Anthonisen criteria [3] present lincreased dyspnoea, increased sputum and sputum purulence). Type 2: two Anthonisen criteria present. Type 3: one Anthonisen criterion present. For exacerbation type, sputum purulence and sputum volume, odds ratios differ by an amount that seems clinically relevant. The $95 \%$ confidence intervals show that a type II error may be responsible for the large p-value for interaction. GOLD: Global Initiative for Chronic Obstructive Lung Disease; GP: general practitioner. 
Former smokers were more likely to fail without antibiotics than current smokers: OR 3.33, 95\% CI 1.45-8.09; p-value for interaction 0.02. We found no other subgroup effects (figure 1).

Former smokers had a greater risk of treatment failure at day 21 without antibiotics than current smokers. This is an unexpected and previously unpublished finding, which we should therefore interpret with caution. There were no additional benefits of antibiotic treatment in any of the other predefined and exploratory subgroups. Notably, the presence of sputum purulence was not associated with less treatment failure if treated with antibiotics. Sputum purulence is associated with bacterial presence [12, 13] and is often used as a justification to prescribe antibiotics. Two randomised trials reported that sputum purulence is associated with treatment failure if not treated with antibiotics [3, 14], but this finding was not confirmed in our trial: failure rates did not differ in type 1 versus type 2/3 exacerbations and exacerbations with or without sputum purulence treated with or without antibiotics. This might be explained by differences in study design and study population. First, concomitant treatment with OCS was regulated per protocol and was prescribed in $95 \%$ of the patients, in contrast with the two previously mentioned trials $[3,14]$; OCS are recommended in all current guidelines as OCS improve lung function and might reduce treatment failure [15]. Second, fever was an exclusion criterion. Third, patients with very severe COPD were excluded.

A strength of this study is the use of data from one of the largest randomised trials in this field. Limitations of an exploratory study are that this does not allow for power calculations. Therefore, negative results may represent type II error. An analysis in which we partitioned our data into tertiles to enhance contrast between the lowest and the highest tertiles also did not demonstrate subgroup effects. Another limitation is that patients with very severe COPD were excluded. As most patients have mild to severe COPD, we think that our results can be extrapolated to most outpatients. Finally, in all cases, the antibiotic was doxycycline. We cannot therefore be sure that our findings can be extrapolated to other antibiotics.

In conclusion, doxycycline has some effect on treatment failure rates at day 21 . However, we did not find clinical characteristics, in particular not sputum characteristics, in patients with mild to severe COPD with an exacerbation without fever that identify those who benefit from antibiotic treatment.

Patricia van Velzen ${ }^{1}$, Gerben ter Riet ${ }^{2,3}$, Paul Brinkman $\oplus^{1}$, Peter J. Sterk ${ }^{1}$ and Jan M. Prins ${ }^{4}$, on behalf of the TEXACOLD study group

${ }^{1}$ Dept of Respiratory Medicine, Amsterdam UMC, University of Amsterdam, Amsterdam, The Netherlands. ${ }^{2}$ Dept of Cardiology, Amsterdam UMC, University of Amsterdam, Amsterdam, The Netherlands. ${ }^{3}$ Urban Vitality Center of Expertise, Amsterdam University of Applied Sciences, Amsterdam, The Netherlands. ${ }^{4}$ Dept of Internal Medicine, Division of Infectious Diseases, Amsterdam UMC, University of Amsterdam, Amsterdam, The Netherlands.

Correspondence: Patricia van Velzen, Dept of Respiratory Medicine, Amsterdam UMC, University of Amsterdam, Meibergdreef 9, 1105 AZ Amsterdam 1081 HV, The Netherlands. E-mail: p.vanvelzen@ amsterdamumc.nl

Received: 27 Feb 2020 | Accepted: 1 April 2020

Support statement: This study was supported by ZonMw grant 80-82310-97-10018. Funding information for this article has been deposited with the Crossref Funder Registry.

This study is registered at www.trialregister.nl with identifier number NTR2499. Individual, deidentified participant data that underlie the results reported in this article will be shared. Additional, related documents, including the study protocol and statistical analysis plan, will be available. Data will become available from 3 months and ending 3 years after publication. Data will be shared with researchers who provide a methodologically sound proposal, to achieve aims in the approved proposal.

Conflict of interest: P. van Velzen reports grants from Netherlands Organization for Health Research and Development during the conduct of the study. G. ter Riet has nothing to disclose. P. Brinkman has nothing to disclose. P.J. Sterk reports that he is a scientific advisor to and has a formal, inconsiderable interest in the SME Breathomix BV, outside the submitted work. J.M. Prins reports grants from Netherlands Organization for Health Research and Development during the conduct of the study.

\section{References}

1 Global Initiative for Chronic Obstructive Lung Disease. Global strategy for the diagnosis, management and prevention of chronic obstructive pulmonary disease. https://goldcopd.org/wp-content/uploads/2018/11/GOLD2019-v1.7-FINAL-14Nov2018-WMS.pdf. Date last accessed: February 3, 2020

2 Vollenweider DJ, Frei A, Steurer-Stey CA, et al. Antibiotics for exacerbations of chronic obstructive pulmonary disease. Cochrane Database Syst Rev 2018; 10: CD010257. 
3 Anthonisen NR, Manfreda J, Warren CP, et al. Antibiotic therapy in exacerbations of chronic obstructive pulmonary disease. Ann Intern Med 1987; 106: 196-204.

4 Miravitlles M, Moragas A, Hernandez S, et al. Is it possible to identify exacerbations of mild to moderate COPD that do not require antibiotic treatment? Chest 2013; 144: 1571-1577.

5 Wedzicha JA, Miravitlles M, Hurst JR, et al. Management of COPD exacerbations: a European Respiratory Society/American Thoracic Society guideline. Eur Respir J 2017; 49: 1600791.

6 National Institute for Health and Clinical Excellence. Chronic obstructive pulmonary disease (acute exacerbation): antimicrobial prescribing. www.nice.org.uk/guidance/ng114. Date last accessed: February 3, 2020.

7 Butler CC, Gillespie D, White P, et al. C-reactive protein testing to guide antibiotic prescribing for COPD exacerbations. N Engl J Med 2019; 381: 111-120.

8 Li Z, Yuan X, Yu L, et al. Procalcitonin-guided antibiotic therapy in acute exacerbation of chronic obstructive pulmonary disease: an updated meta-analysis. Medicine (Baltimore) 2019; 98: e16775.

9 van Velzen P, Ter Riet G, Bresser P, et al. Doxycycline for outpatient-treated acute exacerbations of COPD: a randomised double-blind placebo-controlled trial. Lancet Respir Med 2017; 5: 492-499.

10 Chow AW, Hall CB, Klein JO, et al. Evaluation of new anti-infective drugs for the treatment of respiratory tract infections. Clin Infect Dis 1992; 15: Suppl. 1, S62-S88.

11 Wang R, Lagakos SW, Ware JH, et al. Statistics in medicine - reporting of subgroup analyses in clinical trials. N Engl J Med 2007; 357: 2189-2194.

12 Stockley RA, O'Brien C, Pye A, et al. Relationship of sputum color to nature and outpatient management of acute exacerbations of COPD. Chest 2000; 117: 1638-1645.

13 Miravitlles M, Kruesmann F, Haverstock D, et al. Sputum colour and bacteria in chronic bronchitis exacerbations: a pooled analysis. Eur Respir J 2012; 39: 1354-1360.

14 Miravitles M, Anzueto A. Antibiotics for acute and chronic respiratory infection in patients with chronic obstructive pulmonary disease. Am J Respir Crit Care Med 2013; 188: 1052-1057.

15 Walters JA, Tan DJ, White CJ, et al. Systemic corticosteroids for acute exacerbations of chronic obstructive pulmonary disease. Cochrane Database Syst Rev 2014; 9: CD001288. 